\title{
Recommender systems as "tastemakers": Collaborative filtering as a market strategy for online cultural products
}

\author{
Rose Marie Santini* \\ *Professor, Federal University of Rio de Janeiro - Brazil
}

Abstract

\begin{abstract}
In the cultural market, the operation of which depends on the creation of intersubjective values to generate the production of consumers, the market strategies to adjust supply and demand have been historically characterised by mechanisms of social recommendation; a phenomenon that has intensified and changed on the Internet. The aim of this paper is to discuss the social conditions for the production of belief in symbolic goods and their applications in online markets. Pierre Bourdieu's theory on the field of cultural production provides the conceptual grounding for the proposal of a theoretical study that compares traditional instances of symbolic goods recommendation and today's online recommender systems. This analysis diagnoses the transformation of social processes of influence on online cultural consumption through collaborative filtering and identifies relevant topics for future research in the domain of cultural goods e-commerce.
\end{abstract}

Keywords: Recommender systems, Cultural market, Recommendation of symbolic goods, Social influence. Internet

\section{Introduction}

The consumption of cultural products (music, videos, films, texts, books, games etc.) has become a ubiquitous activity among Internet users and is increasingly integrated into various kinds of online platforms such as Facebook, Youtube and many others. Currently most of the consumption of cultural products has become digital in virtue of the symbolic nature of its content that can be recorded, reproduced and distributed in multiple channels, means of support, systems and manipulated in several different ways.

Each symbolic product is unique and as such engenders a high degree of risk and unpredictability in terms of the time and money allocated for both producers and consumers involved in the cultural market. Due to this characteristic, the marketing strategy for supply and demand adjustment in this market has historically been marked by the presence of mediators which, through their recommendations, have helped produce the demand and influence the decision-making of individuals in order to achieve maximum product absorption by the consumers.

With the exponential increase in the supply of symbolic goods and facilities for their dissemination and use offered by digital technologies, Internet users enjoy a vast array of options. However, in various situations, there is a lack of information available for individuals to select products of their interest and taste. That is why keyword search tools have proven limited as mediators of online cultural consumption, by requiring prior user knowledge (Jeanneney 2007; Pariser 2011).

Recommender systems (RS) which were initially called "intelligent agents" (Negroponte 1970; Maes 1999) emerged in this context. Their development began in the late 1970s, and they were first applied to the Internet in the early 1990s. Several authors (e.g., Resnick \& Varian 1997; Ansari et al. 2000; Adomavicius \& Tuzhilin 2005) point to the emergence of these systems as a solution for searching and discovering items within a universe of excess information on the web. 
To summarize, RS are artificial intelligence-based tools that create user profiles based on present and past consumer preferences, their characteristics or similarities between them, in order to make recommendations to their customers through a content-based filtering approach (Martínez-López et al. 2010), such as Youtube, Amazon, Last.Fm, Rdio, Tidal, Spotify, NetFlix, Google Books, eBay among others. In the current stage of the Internet called Web 2.0, many systems have included in this technology the "collaborative filtering" approach (also used as a synonym for RS), which refers to a type of hybrid software in which information filtering is also performed with human help - that is, with the collaboration of network users, rating the available material in order to generate relevant recommendations among peers.

We expect the emergence and popularization of recommender systems to entail the development of new instances of internet-based mediation, with the onset of competition in the processes of validation and recommendation of cultural products and in the orientation of that market.

The objective of this paper is to investigate the role of recommendation in the social processes of production of belief in symbolic goods and their transmutations in electronic commerce. Based on a review of Pierre Bourdieu's theory on the field of cultural production, a theoretical study is proposed to compare traditional mass media-based recommendation processes with today's online recommender systems. This analysis presents a diagnosis of how the social processes of suggestion and influence in the online cultural market have transformed, from a production perspective.

The rest of the paper is organised as follows: Section 2 describes the circumstances and prevailing commercial strategies that characterise the cultural market and indicates some contradictions implied in this market, established at the limits of the relationship between the economic logic and the public, to then present the research framework. Section 3 shows results of some previous research and draws on different theories to analyse the distinct kinds of social recommendation processes. Section 4 discusses the potential influence of recommender systems and their commercial benefit to the online cultural marketplace. Section 5 presents some examples of the impact of these systems on electronic commerce of cultural products. Finally, the conclusions and future directions of research are presented in Section 6.

\section{The peculiarities of the cultural market: theoretical background}

Recommendation is not a new concept, but it is an operation belonging to the capitalist system. Tete-a-tete recommendation or recommendation within small social groups has always existed in market economies, but through the application of industrial reproduction techniques and the emergence of mass media we have witnessed mass recommendation of symbolic goods. This phenomenon is closely tied to the emergence of the cultural industries (CI).

There are specific aspects of the $\mathrm{CI}$ and the acts of cultural consumption, summarised by Bustamante (2003), which explain the strong presence of symbolic goods recommendation in the mass media as a way of mitigating the inherent uncertainties and risks in this market:

- The importance of creative work constitutes its raw material and cannot be mechanized. This characteristic is related to the pressing need for constant product renewal.

- The "random" nature of the demand: public taste is difficult to predict. 
- Like all information-based products, cultural products are indivisible and inexhaustible goods: consumption does not destroy the product and does not prevent its enjoyment by other consumers.

- The cumulative nature of cultural consumption does not end user demand - on the contrary, it stimulates learning and enjoyment of new products;

- The consumer's uncertainty before buying a product - much higher than in relation to other products - requires a build-up of knowledge often expensive in terms of time and money;

- The need for intermediaries to select works and guide consumption (recommenders such as critics and specialist media vehicles, brands and labels), which act as mediators and help to create social norms of taste.

- The effect of "distinction" or "social differentiation", indicated by Bourdieu (1984 [1979]), linked to the selection of symbolic goods based on each individual's "cultural capital" and, therefore, the multiple, relative and socially determined nature of the cultural values of each time and place.

These elements of risk and uncertainty provide a basis to all the symbolic struggles for the production and imposition of the legitimate vision of the cultural world (Bourdieu 2002). The concept of "cultural capital" here is considered as Lamont and Lareau's (1988) definition: high status cultural signals (attitudes, preferences, formal knowledge, behaviors, goods and credentials) used for social and cultural exclusion. The difficulty companies involved in the cultural market have is related to the fact that, for cultural products, the production depends on "customer creation", that is, the creation of tastes, needs and belief in those goods. According to Bourdieu (2008 [1984]), to avoid a reductive "economistic" analysis, it is necessary to analyse the social processes of mediation through which the CI can impose their products, artists, works, genres and styles, thus helping to lay down specific definitions of the needs and tastes in a given era and a given market.

\section{The production of demand through recommendation}

One of the primary strategies in the process of "demand production" is the recommendation of cultural products; a now omnipresent strategy in all media vehicles (newspapers, magazines, radio, film, television), taking an explicitly (advertising) or implicitly (editorials or schedules) commercial shape. Therefore, there is a symbiotic relationship between the editorial space and advertising space of the mass media that prescribes the recommendation of cultural products. This combination of different media channels produces belief in the value of certain goods, which in turn develops into a dual framework of accumulated "symbolic capital" and "economic capital".

For Bourdieu (1980), in the belief production process that supports the economy of cultural goods, the only useful and efficient capital corresponds to what the author calls "prestige". As "cultural authority", prestige can only guarantee specific gains produced by the field if it is converted into symbolic capital. In other words, it is a matter of accumulating "recognition capital" which leads to a power of legitimising productions or people through judgments and classifications - and, therefore, giving value to and obtaining benefits from this operation in a given field or market. 
When selecting and reporting the value of symbolic goods by disseminating opinions and suggestions, the mass media act as "cultural bankers" (Bourdieu 1980, p. 262); that is, as "guarantors of the quality of the works", offering their audience or readers their accumulated wealth of symbolic capital as guarantee of the validity of the information and suggestions conveyed. This guarantee corresponds to the principal investment that drives the $\mathrm{CI}$ market and that allows their products penetrate the cycle of recognition and major economic return.

However, the fight for appropriation of "recognition capital" in the cultural field is not sufficient to sustain the strong participation of its mediators. According to Bourdieu (1985), the struggle for symbolic power occurs in parallel to those agents' inherent need to accumulate economic capital. This dual imperative, which is often contradictory in the artistic and cultural field, has been instigating a profound change in the recommendation spaces.

The need for growing return on advertising brings about a deterioration of the traditional role of independent critics in mass media vehicles. The recommenders often become employees of such companies and are subjected to editorial filters. In many cases the "cultural authority" becomes bound to the actual corporate brand of the media vehicles ${ }^{1}$. However, this generalised commercial conversion of the spaces of divulgation, legitimation and recognition of symbolic goods has significant social implications, closely related to the conditions of belief flows that intersect the cultural market.

\section{"Disinterested recommendation" vs. "commercial recommendation": conditions for the production of} belief in symbolic goods

According to Bourdieu (1980), the fields of cultural production are universes of belief that can only function to the extent that they can produce, indistinctly, the products and the needs for those products through practices that go against the usual criteria of the "economy". That is to say the struggles that develop in the circle of cultural belief are decisive conflicts that undermine "economic" relations.

Those who believe in the value assigned to goods, works and artists, and support themselves on that faith to conduct their cultural habits, condemn explicitly commercial interests and practices and the calculated use of accumulated "recognition capital" that acts through subjection to market demands (Bourdieu, 1980). That same idea is also defended by Kelley $(1967 ; 1973)$ through the "attribution theory", in which he proposes that a communicator will be perceived as biased if the receiver can infer that the message is attributed to situational motives or self-benefit.

According to Bourdieu's "law of the cultural goods universe" (1980), return on an investment will be more productive from a symbolic point of view the less that is declared. This forces promotional actions, corresponding to open advertising in the business world, to take on a euphemistic character in order to generate belief in the cultural field. This means that recommendation can only help produce value of a

1 This situation is clear in the cultural market environment, especially in the print media (newspapers and magazines). Concerts, plays, records, books and films are frequently legitimized and recommended by the mass media as guarantee of the quality of the works. For example, labels linked to products such as "recommended by Time magazine", "recommended by the New York Times" etc. can be found in editorial spaces, in promotional pieces and even in the packaging of some products. 
certain product, work or artist if it successfully disguises the explicitly commercial manoeuvres, replacing them with milder, more discreet forms of promotion and suggestion. Following the author's argument, openly "commercial" recommendations tend to generate a partial distrust among recipients in terms of their relevance and credibility, while recommendations perceived as "disinterested" are more likely to generate attribution of social value.

Therefore, strategies to "create" (or stabilize) the flows of belief and desire through contagion are shaped by mechanisms of social control and involve elements of constraint, enforcement, stimulation and seduction, however their power and applicability are not immutable across different times, locations and contexts. Cultural habits are only created and disseminated as a result of a complex and contradictory process against the strategies of competitors in the market with the wishes, expectations, hopes and points of resistance of the consumers. This is how the demand holds structural sway on the supply; by way of acceptances or rejections of the proposed solutions in terms of production, forcing adjustments and changes on the supply side. Therefore, adapting the ways to stimulate demand is a key issue in the new spheres of consumption; and this is now being perceived in the digital environments.

\section{Discussion of framework}

Disputes in the symbolic goods marketplaces have intensified with the emergence and increasing penetration of digital information and communication technologies (ICTs) in all spheres of everyday social life. In recent years, recommender systems have become established as the main mediators and guides for online cultural consumption and currently constitute the technology of the leading cultural product websites, such as Youtube, Amazon, Pandora, Spotify, Last.fm, Tidal, iLike, NetFlix, Google Books, eBay, Yahoo Music, ChoiceStream, NewsMe, Genius and Ping (iTunes platform). These systems are large-scale interactive platforms with commercial applications where information items are displayed and recommended to users according to individual preferences and interests, such as songs, movies, videos, books, articles, news, etc. Against this backdrop, this article suggests that the social processes that influence people's cultural habits are being modified in the online environment, and the recommendation systems that accompany them are key agents in this set of transformations. While the Internet and its platforms for cultural consumption leverage some trends triggered by the classic cultural industries, they also deeply modify some aspects of the social process of production of belief in symbolic goods and of the logic of cultural habit propagation. However, the questions raised regarding this proposition should avoid technological determinism, which is based on the principle of extracting the quality of cultural change from the nature of technology. Given the omnipresence of the media and of the Internet access, it is necessary to: (a). Understand the variables that affect social recommendation processes that determine the degrees of relevance and credibility (topic addressed in Section 3); (b). Analyse the peculiarities of symbolic goods as "products of belief" to discuss the potential influence of RS in the cultural field (addressed in Section 4); (c). Observe the extent to which new instances of cultural mediation guide the social frameworks for construction of meaning and value, and how changes can affect the electronic markets (addressed in Section 5). 


\section{The variables in social recommendation processes}

The sociology of culture perspective introduced by Gabriel Tarde (1969; 2000 [1890]) and subsequently followed up by Paul Lazarsfeld et al. (1948; 2009 [1955]) and partially resumed by Pierre Bourdieu (1984 [1979]), among others, proposes the investigation of the social patterns implied in the diffusion of opinions, preferences and cultural attitudes. These authors consider personal suggestions conveyed at a micro-social level as the most powerful instrument for spreading beliefs and desires and triggering imitative series in the sphere of social uses. According to Lacroix \& Tremblay (1997), the concept of social uses refers to the rules of collective conduct that are not deemed to be imposed or mandatory, but rather "incorporated" or "naturalized" by individuals.

Several researchers (e.g. Ardnt 1967; Olshavsky \& Granbois 1979; Price \& Feick 1984; Duhan et al. 1997; Gilly et al. 1998) have extended this theoretical perspective with the notion that the nature of the information sources (personal or impersonal) ${ }^{2}$ and the types of recommendation (personalised or non-personalised) correspond to the variables that modify the scope of influence on the individuals' decision. Kelman (1961) suggests that these variations affect how recipients perceive the message and define the degree of credibility and value of the information. In other words, the effectiveness of the recommendations depends on how these variables cross over and generate different types of process. To help illustrate this notion, we suggest the organization of the types of social recommendation processes as follows:

Table 1: Types of social recommendation processes

\begin{tabular}{|l|l|l|l|l|}
\hline Type & $\begin{array}{l}\text { Information } \\
\text { Source }\end{array}$ & $\begin{array}{l}\text { Type of } \\
\text { Recommendation }\end{array}$ & $\begin{array}{l}\text { Type of } \\
\text { Communication }\end{array}$ & Example \\
\hline A & Personal & Personalised & One-to-one & $\begin{array}{l}\text { Suggestions by friends and } \\
\text { acquaintances }\end{array}$ \\
\hline B & Personal & Non-personalised & One-to-one & Vendors \\
\hline C & Personal & Non-personalised & One-to-many & Suggestions by experts and critics \\
\hline D & Impersonal & Non-personalised & One-to-many & Mass media \\
\hline E & Impersonal & Non-personalised & Many-to-many & Reports by other consumers \\
\hline F & Impersonal & Personalised & Many-to-many & Recommender systems \\
\hline
\end{tabular}

For Brown \& Reingen (1987) the types of information sources and recommendation correspond to the different degrees of influence on consumer decision making. Based on empirical investigations, the authors demonstrated that the "type of recommendation" is the primary indicator for determining the relevance of the message. Information received through sources that involve some personal knowledge about the recipient (personalised recommendation) has a greater influence on individuals' behaviour than nonpersonalised recommendations.

Subordinate to the this first variable "type of recommendation", personal information sources tend to be partially more influential than those classed as impersonal, however they do not correspond to a determinant

\footnotetext{
${ }^{2}$ Sources are considered personal when the information is given by someone who is known and recognized, and impersonal when one cannot precisely identify who is issuing the message.
} 
factor in all cases as they fail to guarantee individual relevance of the recommendation (Brown \& Reingen 1987). For example, even among friends and acquaintances, people have different interests, tastes, beliefs, opinions or social position and may not characterise a community of practice (CoP) ${ }^{3}$.

Therefore, drawing on a review of the literature regarding this matter, one could envisage a likely hierarchy of the types of recommendation mentioned in Table 1, according to their potential influence. Considering the results presented by Brown \& Reingen (1987), this article recognises that the process of interpersonal suggestion tends to be the most influential in determining cultural practices, but we propose that recommendations mediated by collaborative filtering-based recommender systems are the second most influential type of recommendation in electronic environment decision-making. This assertion may be construed as risky, yet plausible in some cases, and the conditions for its validity are worthy of discussion and investigation.

Several theoreticians and researchers in the social science field have devoted their attention over recent decades to comparisons and analyses of the influence of recommendation types A, B, C, D and E (see Table 1) on process of forming opinions, taste and decision-making, and the modes of subjectification they each imply. However, little is known about the social influence of type F suggestions - which have emerged recently with the Internet - and how this new recommendation type, through RS, can affect the cultural perceptions, decisions, practices and preferences of their users.

In an attempt to incorporate "computer-mediated recommendation environments" into the investigative agendas about the processes of suggestion and influence of social behaviour, a new area of research has emerged in an interdisciplinary field (e.g. Barry 1994; Alba et al. 1997; Balabanovic \& Shoham 1997; Duhan et al. 1997; Basu et al. 1998; Maes 1999; Urban et al. 1999; West et al. 1999; Ansari et al. 2000; Adamic \& Huberman 2002; Häubl \& Trifts 2000; Senecal \& Nantel 2004; Adomavicius \& Tuzhilin 2005; Martínez-López et al. 2010; Lee, Cho \& Kim 2016, and others).

However, when reviewing specific publications about online recommender systems, one observes a predominance of studies in the field of computer science and artificial intelligence, dedicated to functional development and analysis, rather than empirical and theoretical diagnoses in the fields of sociology, marketing, and communication about the influence of such systems in the online consumption arena (Ying et al. 2006; Xiao \& Benbasat 2007). There is a particular lack of studies that consider how the potential influence of these systems varies for different types of product, especially those related to social patterns implied in the recommendation of symbolic goods.

\footnotetext{
3 The notion of community of practice (CoP) was developed by Jean Lave and Etienne Wenger (1991). Wenger (2000) defines that communities of practice are groups of people who share a concern or a passion for something they do and learn how to improve as they interact regularly. This definition allows for, but does not assume, intentionality. A community of practice is not merely a club of friends or a network of connections between people. It has an identity defined by a shared domain of interest where members engage in joint activities and discussions, help each other, share information and practice.
} 


\section{The potential influence of collaborative filtering on cultural consumption}

The first empirical study about the influential power of RS on consumer decision-making was presented by Sylvain Senecal and Jaques Nantel in 2004. The main scientific implication of that study was the presentation of results comparing different types of recommendation, showing that the suggestions emitted by these systems are the most influential on user behaviour. Items recommended by the RS were shown to be twice as likely to be selected in relation to other types; with the exception of recommendations conveyed at an interpersonal level.

According to the authors, such likelihood remains inclusive when the individuals perceive that the RS suggestions carry less expertise than the opinion of "human experts" or that the systems are part of a commercial set-up, in other words, when they assume some sort of profit through direct or indirect sales of products. However, as Urban et al. (1999) suggest, the information sources do not gain credibility instantaneously. User trust in the system grows following multiple successful interactions, that is, it depends on previous experiences deemed satisfactory and relevant.

Senecal and Nantel (2004) review the recommendation process of two different product types classified according to their "search" and "experience" qualities ${ }^{4}$. According to Nelson (1974, p. 730), the "search qualities" are identified when "the consumer can determine the attributes of the product by inspection prior to purchase". Meanwhile, "experience qualities" refer to goods that "cannot be determined prior to experimentation", however when experiencing a part one can know the whole.

This comparative strategy was chosen based on prior studies (e.g. Bearden \& Etzel 1982; Childers \& Rao 1992; King \& Balasubramanian 1994) that revealed that the product type affects the relation between consumers and recommendation sources and modifies the potential influence. Upon comparing the impact of RS suggestions on user decisions, Senecal \& Nantel (2004) found that individuals are more dependent on recommendations when dealing with decisions about "experience products". However, as the authors acknowledge, the results of the investigation are limited to these two types of consumer goods and only address selection processes, without verifying the impact on purchase decisions.

According to Resnick (1999), "online recommendation through recommender system algorithms demonstrate greater potential of use in situations where the user decision is a matter of taste" and is directly related to the recommendation of cultural products, which correspond to a third class of products.

Peltier (2007) maintains that there is a type of consumer good that can be classified as having belief-based qualities. These are identified as symbolic and cultural goods (for example, books, films, songs, videos, etc.) the attributes of which "can only be grasped after their full consumption". Therefore, the criteria that condition consumer decision-making and define choices prior to use can only be based on belief in their value.

The classification of symbolic goods as "products of belief" endorses the argument about the existence of a strong "social demand" for recommender systems of online cultural products. In the online environment, despite the wide variety of products offered to consumers, excessive options can discourage people from concluding their search and selection processes for a purchase (Martínez-López et al. 2010; Haynes 2009;

4 The authors analyzed different information sources and their impact on consumer decision-making in relation to the choice of calculators ("search good") and wine ("experience good"). 
Iyengar \& Lepper 2000; Schwartz 2004; Lee, Cho \& Kim 2016). The potential influence of these systems in guiding demand in the cultural market and their impact on e-commerce may be illustrated with a few examples, presented below.

\section{The impact of recommender systems on cultural market}

The social relevance of RS is clearly revealed in the field of online music consumption, which has reached and remained at the forefront of the cultural industry. The music sector has represented a laboratory of experimentation for technological and commercial innovations due to the rapid decline of its traditional business models on the Internet.

Until 2008 Last.fm was the leading online music recommender systems with over 37 million direct and 19 indirect users, distributed among 280 countries worldwide, and with a library of over 150 million songs registered by 280,000 record companies and over 16 million independent artists (Miller et al. 2008). According to a report issued by the CBS Corporation (2008) - which currently controls Last.fm - song and artist recommendations through its system led to a $119 \%$ increase in CD sales and song downloads on Amazon following the two companies' agreement to work in partnership. In the same year, that result triggered the creation of commercial agreements with the two largest online music stores: iTunes and 7Digital. Subsequently, other music platforms, such as Spotify, MOG, Hyper Machine, We7 and VEVO, also established partnerships with the company (Ogle 2010). Last.fm formerly offered a radio streaming service based on a recommender system algorithm, which was discontinued on April $28^{\text {th }} 2014$ (Last.fm 2014). The ability to access the large catalogue of music stored on the site was later entirely removed, replaced by links to YouTube and Spotify (Last.fm 2015).

In the last years, Spotify became the global leader of streaming and recommendation service (IFPI 2017, p. 17). In July 2017, Spotify had more than 140 million monthly active users and more than 60 million paying subscribers distributed among 60 countries worldwide, with a library of over 30 million songs and 2 billion different playlists (Spotify 2017).

Spotify pays royalties based on the number of songs streamed on the service and this is rescuing record companies from the last 15 years crises, when the industry lost nearly $40 \%$ of its revenues. In 2016 , the global recorded music market grew by $5.9 \%$, the fastest rate of growth since IFPI began tracking the market in 1997 (IFPI 2017). According to IFPI $(2017$, p.10) on-demand and recommendation music streaming has been the clear driver of this growth, with revenues surging by $60.4 \%$. With more than 100 million users of paid subscriptions globally, it makes up the majority of digital revenue which now accounts for $50 \%$ of total recorded music revenues.

The "Discover Weekly" Spotify service is the major strategy of the company to recommend personalized content. This service automatically generates a personally tailored playlist of two to three hours of music for registered users every week (Popper 2015). It works as a kind of "curatorship" in streaming music, whereby Spotify offers a combination of human editorial and algorithmically generated selections (and maybe a portion of payola).

The same trend in music consumption can be seen in relation to other kinds of online cultural products. According to Afuah (2014, p. 253) more than $60 \%$ of movies requested thought Netflix website are 
determined by its recommender system. Although their Chief Product Officer and vice-president, respectively Neil Hunt and Carlos A. Gomez-Uribe, indicated that 80 percent of movies watched on Netflix came through recommendations and placed the value of Netflix recommendations at more than US $\$ 1$ billion per year (Hunt \& Gomez-Uribe 2016; Smith \& Linden 2017).

On Google News, recommendation is accountable for $38 \%$ of the clicks on news items through its site (Lamere \& Celma 2007, p.12-13). In 2010, YouTube reported using Amazon's algorithm for recommending videos (Davidson, Liebald \& Liu 2010). In 2015, 30 percent of Amazon.com's page views were from recommendations (Sharma, Hofman \& Watts 2015; Smith \& Linden 2017).

These numbers reinforce the idea that users not only consider such systems as useful for selecting cultural products on the Internet, but are also highly susceptible to their recommendations. Another advantage demonstrated by these numbers is that, unlike advertising carried by the mass media, the degree of influence of recommendations generated by RS on consumer decision-making in online markets can be precisely measured.

The popularity of online RS is due to their hybrid approach, based on the ability to generate personalised suggestions (drawing on the extraction and cross-referencing of data available about their user networks), combined with their collaborative nature, which attributes are perceived by the users as indicative of relevance and impartiality, respectively (Komiak \& Benbasat 2006; Xiao \& Benbasat 2007). By crossreferencing profiles on their databases, the systems manage to group individuals into small clusters, according to their use similarity, but without losing sight of their likely differences and multiple intersubjective connections, which mean that one person may simultaneously belong to various CoP. In this context, one can recognise a social belief that privileges the power of machines in information processing which results in recommendations based on statistics and probabilities that define value criteria; a phenomenon which has emerges on the Internet as a very special process of social contagion.

\section{Conclusions and future research directions}

In conclusion, the symbolic goods market involves a high degree of uncertainty and risk compared to others, both in terms of production and consumption. This particular aspect (which is due to the nature of the product) becomes more evident in e-commerce, which presents new challenges for marketers and offers various opportunities for future research.

This article anticipates that recommender systems will develop as a sophisticated socio-technical and economic solution, not only for excess online information, but also as a demand guidance strategy in these environments. In the online cultural market, where infinite variety and the need for personalisation are the primary characteristics, the function of these systems is precisely to stimulate the production of different practices and preferences that are able to act in conjunction with the vast diversity of the supply and thus help engage commercial activities.

The uses and applications of RS for electronic business are not dissimilar to demand limitation-stimulation games, analogous to the role of advertising in the mass media, however the functional framework of these systems consists of important innovations that indicate profound intersubjective effects on the processes of producing belief in symbolic goods and the propagation of cultural habits. 
Through investigating the functional framework of RS and their effects on the cultural market, it is suggested here that collaborative filtering can operate so as to capture, organise and, above all, simulate the generation of word-of-mouth (WOM) suggestions and their diffusion within the CoP. The capacity to manage the mechanisms of WOM information transmission among millions of interconnected users on their platforms represents the most relevant social factor that tends to position RS as important tastemakers of a large number of Internet users, however this hypothesis required empirical testing.

Considering the power of recommender systems in the field of cultural production, there is a need for further studies based on experiments and statistical data in order to specify the degree of influence such systems hold in determining cultural preferences and practices and to compare the credibility and value of their suggestions against other information sources and types of recommendation. In this regard, it is of utmost importance to develop comparative case studies that analyse the effect of these systems on different sectors of the cultural industries, so as to weigh up their specific characteristics. We need to determine the differences in the processes of social contagion of belief and desire in the fields of music, videos, films, games, books, etc. In light of such a challenge, RS constitute a priority area for investigation and data collection due to the possibilities they offer for non-obstructive observation.

Furthermore, while numerous studies start to emerge about the processes of influence among friends and acquaintances connected through online social networking platforms (ONSP), research is required into how these ONSP are related to the RS in spreading certain items at a global level and determining the popularity of such information items. For instance, we must understand how an amateur video, when made available on Youtube (which has its own recommender system) manages to spread rapidly among millions of interconnected users and reach the top ten of most viewed videos on the Internet in certain periods of time, regardless of any content analysis, which constitutes a constant Internet phenomenon.

Finally, it should be considered that the majority of Internet users are still learning and becoming familiar with the various options presented by RS technology, however their use is already becoming a priority in people's everyday habits, which may encourage or inhibit the dominance of certain commercial strategies over others. Therefore, this work points to a research agenda in the social sciences, in particular sociology and communication, that considers the social implications of recommender systems in online environments of production, mediation, diffusion, consumption and use of cultural goods that might contribute to enhancing all the agents involved in that market.

\section{References}

Adamic, A., \& Huberman, B. Zipf's law and the internet. Glottometrics, 3, p. 143-150, 2002.

Adomavicius, G., \& Tuzhilin, A. Toward the next generation of recommender systems: a survey of the stateof-art and possible extension. Ieee transaction on knowledge and data engeneering, 17 (6), p. 734-748, 2005.

Afuah, A. Business model innovation: concepts, analysis, and cases. New york: routledge, 2014.

Alba, J., et al. Interactive home shopping: consumer, retailer, and manufacturer incentives to participate in electronic marketplaces. Journal of marketing, 61(3), p. 38-53, 1997. 
Ansari, A., Essegaier, S., \& Kohli, R. Internet recommendation systems. Journal of marketing research, 3ᄌ(3), p. 363-375, 2000.

Ardnt, J. Role of product-related conversations in the diffusion of a new product. Journal of marketing research, 4(3), p. 291-295, 1967.

Balabanovic, M., \& Shoham, Y. Fab: content-based, collaborative recommendation. Communication of acm, $40(3)$, p. 66-72, 1997.

Barry, C. L. User-defined relevance criteria: an exploratory study. Journal of american society for information science, 45, p. 149-159, 1994.

Basu, C., Hirsh, H., \& Cohen, W. Recommendation as classification: using social and content-based information in recommendation. Proceeding of the american association for artificial inteligence. Ca, usa, 1998.

Bearden, W. O., \& Etzel, M. J. Reference group influence on product and brand purchase decisions. Journal of consumer research, 9(2), p. 183-194, 1982.

Bourdieu, P. Cuestiones de sociología. Madrid: akal, 2008 [1984].

. Distinction: a social critique of the judgement of taste. Cambridge, ma: harvard university press, 1984 [1979].

. The field of cultural production, or: the economic world reversed. Poetics 12, p. 311-356, 1985.

. The production of belief: contribution to an economy of symbolic goods. Media culture \& society, 2(3), p. 261-293, 1980.

. Cultural power. In: spillman, I., (ed.) Cultural sociology. Oxford: blackwell, p. 69-75, 2002.

Brown, J. J., \& Reingen, P. H. Social ties and word-of-mouth referral behavior. Journal of consumer research, 14(3), p. 350-362, 1987.

Bustamante, E. Hacia un nuevo sistema mundial de comunicación: las industrias culturales en la era digital, 2. Barcelona: gedisa, 2003.

Cbs corporation. Press realease cbs corporation 1st quarter 2008: key developments \& initiatives, 4 (7), 2008.

Childers, T. L., \& Rao, R. The influence of familial and peer-based reference groups. Journal of consumer research, 19(2), p. 198-212, 1992.

Davidson, J.; Liebald, B.; Liu, J. (2010). The youtube video recommendation system. Proc. 4th acm conf. Recommender systems, p. 293-296.

Duhan, D. F., Johnson, S. D., \& Wilcox, J. B. Influences on consumer use of word-of-mouth recommendation sources. Journal of the academy of marketing science, 25(4), p. 283-295, 1997.

Gilly, M. C., Graham, J. L., \& Wolfinbarger, M. F. A dyadic study of personal information search. Journal of the academy of marketing science, 26(2), p. 83-100, 1998.

Gomez-Uribe, C. A.; Hunt, N. The netflix recommender system: algorithms, business value, and innovation. Acm trans. Management information systems, v. 6(4), p. 1-19, 2016.

Häubl, G., \& Trifts, V. Consumer decision-making in online shopping environments: the effects of interactive decision aids. Marketing science, 19(1), p. 4-21, 2000.

Haynes, G. Testing the boundaries of the choice overload phenomenon: the effect of number of options and time pressure on decision difficulty and satisfaction. Psychology and marketing, 26(3), p. 204-212, 2009. 
Ifpi. Global music report 2017: annual state of the industry. Available at: http://www.ifpi.org/news/ifpiglobal-music-report-2017. Accessed 10 august 2017.

Iyengar, S., \& Lepper, M. When choice is demotivating: can one desire too much of a good thing? Journal of personality and social psychology, 79(6), p. 995-1006, 2000.

Jeanneney, J-N. Google and the myth of universal knowledge: a view from europe. Chicago: the university of chicago press, 2007.

Kelley, H. H. Attribution theory in social psychology. In: d. Levine (ed.), nebraska symposium on motivation (pp. 192-241). Lincoln, ne: university of nebraska press, 1967.

Kelley, H. H. The process of causal attribution. American psychologist, 28, p. 107-128, 1973.

Kelman, H. C. Processes of opinion change. Public opinion quarterly, 25, p. 57-78, 1961.

King, M. F., \& Balasubramanian, S. K. The effects of expertise, end goal, and product type on adoption of preference formation strategy. Journal of the academy of marketing science, 22(2), p. 146-159, 1994.

Komiak, S., \& Benbasat, I. The effects of personalization and familiarity on trust and adoption of recommendation agents. Mis quarterly, 30, (4), p. 941-960, 2006.

Lacroix, J.-G., \& Tremblay, G. The "information society" and cultural industries theory. Current sociology, 45, (4), 1997.

Lamere, P., \& Celma, O. Music recomendation tutorial. Proceedings of the 8th international conference on music information retrieval (ismir '07). Vienna, austria: austrian computer society, p. 411-416, 2007.

Lamont, M. \& Lareau, A. Cultural capital: allusions, gaps and glissandos in recent theoretical developments. Sociological theory, vol.6(2), p. 153-168, 1988.

Last.fm. Changes to last.fm subscriptions. 26 november 2014. Available at: https://www.last.fm/announcements/subscriptions2014, accessed 10 august 2017.

Last.fm. Artists and labels: how to make the most of last.fm. Last.fm community. 2015. Available at: https://getsatisfaction.com/lastfm/topics/artists-and-labels-how-to-make-the-most-of-last-fm. Accessed 10 august 2017.

Lave, J. \& Wenger, E. Situated learning: legitimate peripheral participation. Cambridge: cambridge university press, 1991.

Lazarsfeld, P., \& Katz, E. Personal influence: the part played by people in the flow of mass communications. New brunswick, new jersey: transaction publisher. $2^{\circ}$ ed, 2009 [1955].

Lazarsfeld, P., \& Merton, R. K. Mass communication, popular taste, and organized social action. In: bryson, I. Communication of ideas. New york: harper \& brothers, 1948, p. 95-118.

Lee, J. H.; Cho, H., \& Kim, Y.-S. Users' music information needs and behaviors: design implications for music information retrieval systems. Journal of the association for information science and technology, $\mathrm{p}$. 1301-1330, 2016.

Maes, P. Smart commerce: the future of intelligent agents in cyberspace. Journal of interactive marketing, 13(3), p. 66-76, 1999.

Martínez-lópez, F. J. Et al. Psychological elements explaining the consumer's adoption and use of a website recommendation systems: a theoretical framework proposal. Internet research, 20(3), p. 316-341, 2010. 
Miller, F., Stiksel, M., \& Jones, R. Last.fm in numbers. In: last.fm press material. London, uk: cbs interative, february, 2008.

Negroponte, N. The architecture machine. Boston: mit press, 1970.

Nelson, P. Information and consumer behavior. Journal of political economy, 78(2), p. 311-329, 1970.

Advertising as information. Journal of political economy, 83(4), p. 729-754, 1974.

Ogle, M. (2010). Yes it does. 12 april, 2010. Blog last.fm. Available at: http://blog.last.fm/2010/04/12/yesit-does. Accessed 22 october 2011.

Olshavsky, R., \& Granbois, D. H. Consumer decision-making - fact or fiction. Journal of consumer research, 6(2), p. 93-100, 1979.

Pariser, E. The filter bubble: what the internet is hiding from you. London: penguin group, 2011.

Peltier, S. Les industries culturelles, une exception économique? In: culture, etat et marché, cahiers français. L'économie de la culture 312, p. 31-36, 2007.

Popper, B. Tastemaker: how spotify's discover weekly cracked human curation at internet scale. The verge. 30 ${ }^{\text {th }}$ september, 2015. Available at: https://www.theverge.com/2015/9/30/9416579/spotifydiscover-weekly-online-music-curation-interview. Accessed 10 august 2017.

Price, I. L., \& feick, I. F. (1984). The role of recommendation sources in external search: an informational perspective. In: kinnear, t. Advances in consumer research, 11. Provo, ut: association for consumer research, 1984, p. 250-255.

Resnick, P. Recommender systems - interview. [1999]. University of michigan school of information. Available at: www.umich.edu. Accessed 10 march 2008.

Resnick, P., \& Varian, H. R. Recommender systems. Communication of the acm, 40 (3), p. 56-58, 1997.

Sharma, A.; Hofman, J.M.; watts, d.j. estimating the causal impact of recommendation systems from observational data. Proc. 16th acm conf. Economics and computation, p. 453-470, 2015.

Spotify. About - fast facts. Available at: https://press.spotify.com/es/about/. Accessed 10 august 2017.

Smith, B.; Linden, G. Two decades of recommender systems at amazon.com. Ieee internet computing,v. 21(3), p. 12-18, 2017.

Schwartz, B. The paradox of choice: why more is less. New york, ny: harpercollins, 2004.

Senecal, S., \& Nantel, J. The infuence of online product recommendations on consumers' online choises. Journal of retailing, 80(2), p. 159-169, 2004.

Tarde, G. On communication and social influence - selected papers. Chicago: university of chicago press, 1969.

Tarde, G. Social laws: an outline of sociology. Kitchener: batoche books, 2000 [1890].

Urban, G., Sultan, F., \& Qualls, W. Design and evaluation of a trust based advisor on the internet (working paper 40). E-commerce research forum, mit, 1999.

Wenger, E. Communities of practice. New york: cambridge university press, 2000.

West, P. M., et al. Agents to the rescue? Marketing letters, 10(3), p. 285-300, 1999.

Xiao, B., \& Benbasat, I. E-commerce product recommendation agents: use, characteristics, and impact. Mis quarterly, 31(1), p. 137-209, 2007.

Ying, Y., Feinberg, F., \& Wedel, M. Leveraging missing ratings to improve online recommendation systems. Journal of marketing research, 43(3), p. 355-365, 2006. 